Instructions for authors, subscriptions and further details:

http://brac.hipatiapress.com

\title{
El Mito de la Mezcla Óptica Impresionista
}

\section{Diego Gómez Sánchez ${ }^{1}$}

1) Departamento de Arte de la Facultad de Bellas Artes de Cuenca (Universidad de Castilla-La Mancha). España

Date of publication: October $3^{\text {rd }}, 2014$

Edition period: October 2014-February 2015

To cite this article: Gomez Sánchez, D. (2014). El Mito de la mezcla óptica impresionista. Barcelona, Research, Art, Creation, 2(3), 301-326. doi: 10.4471/brac.2014.15

To link this article: http://dx.doi.org/10.4471/brac.2014.15

\section{PLEASE SCROLL DOWN FOR ARTICLE}

The terms and conditions of use, except where otherwise noted, are related to the Open Journal System and to Creative Commons Attribution License (CCBY). The indication must be expressly stated when necessary. 
BRAC - Barcelona Research Art Creation. Vol. 2 No. 3, October 2014, pp. 301-326

\title{
The Myth of the Impressionist Optical Mixture
}

Diego Gómez Sánchez

University of Castilla-La Mancha

(Received: 21 May 2014; Accepted: 13 August 2014; Published: 3 October 2014)

\begin{abstract}
The appearance on the Parisian art scene of the works of Seurat and Signac in the eighth Impressionist Exhibition (1886) produced the erroneous comparison between some divisive technical approaches and the pure Impressionists ones, especially the one which is attributed to the use of optical mixing color, i.e. color fragmentation in the components and the reconstruction of tone in the retina of the viewer. This article attempts to investigate the causes, history, genesis and evolution of the myth, which has puzzled eminent historians, critics and artists and that persists today backed up by the principle of authority.
\end{abstract}

Keywords: painting, optical mixing, color, Impressionism, Post-Impressionism 
BRAC - Barcelona Research Art Creation. Vol. 2 No. 3, October 2014, pp. 301-326

\section{El Mito de la Mezcla Óptica Impresionista}

Diego Gómez Sánchez

Universidad de Castilla-La Mancha

(Recibido: 21 Mayo 2014; Aceptado: 13 Agosto 2014; Publicado: 3 Octubre 2014)

\section{Resumen}

La aparición en la escena artística parisina de las obras de Seurat y Signac en la octava exposición impresionista (1886) dio pie a una errónea equiparación entre algunos planteamientos técnicos divisionistas con los de los impresionistas puros, especialmente el que atribuye a éstos el uso de la mezcla óptica del color, es decir, la fragmentación del color en sus componentes y la reconstrucción del tono en la retina del espectador. Este artículo trata de indagar en las causas, antecedentes, génesis y evolución del mito, que ha confundido a eminentes historiadores, críticos y artistas y que persiste hasta nuestros días respaldado por el principio de autoridad.

Palabras clave: pintura, mezcla óptica, color, Impresionismo, Postimpresionismo 
E

1 impresionismo es pródigo en mitos, y esta riqueza marca, con una rotundidad muy superior a la de ninguna otra consideración, la medida de su enorme popularidad. Buena parte de este catálogo de mitologías se ha consolidado en la imaginación popular gracias al abono esparcido por la leyenda del artista-sufridor a la que el impresionismo ha contribuido grandemente con figuras y anécdotas más o menos maquilladas: pobreza extrema y dilatada, camaradería sin fisuras, rechazo casi unánime y prolongado de la crítica y del favor del gran público, convicciones inquebrantables, abominación de los cauces institucionalizados del arte, paisajismo à plein air por adversas que fueran las condiciones meteorológicas... Sin embargo, el mito impresionista que con mayor tenacidad ha resistido la erosión del descrédito tiene que ver con el supuesto seguimiento por los pintores de la mezcla óptica del color. Su formulación más común sería más o menos la siguiente: Monet, Renoir, Sisley y Pissarro apenas mezclaban sus colores en la paleta; por el contrario, aplicaban sobre la tela pinceladas separadas de un puñado de colores elementales o básicos con el propósito de que, contemplado el cuadro a una distancia conveniente, el ojo del espectador compusiese el color resultante mediante la fusión de aquéllos en la retina. El resultado de este procedimiento, perseguido a conciencia por artistas expertos en teoría cromática, sería la obtención de coloraciones mucho más intensas y luminosas que las que hubiese permitido la mezcla física o matérica de los pigmentos, puesto que los colores sujetos a mezcla retiniana se comportan de forma semejante a como lo hacen los rayos de luz. Así pues, del mismo modo que el impresionista pinta suelto y con una factura abierta para que el ojo del espectador "complete" la forma, también pinta sin mezcla real para que ese mismo ojo complete el trabajo que la mano deja inacabado, pero no desde luego por prisa, impericia o indolencia, sino porque el artista había llegado a la conclusión de que era éste el único procedimiento viable para superar la cortedad de los medios cromáticos, incapaces de otro modo de satisfacer su insaciable apetencia de luminosidad y centelleo. Esto es algo que casi todo el mundo cree saber de buena tinta en relación con el impresionismo, una suerte de dogma de fe de suscripción tan apresurada como irreflexiva y que llevaría a más de uno a comprometer su credibilidad y a arriesgarse a pasar la ordalía suprema del hierro candente. Lo más llamativo del caso es que, hasta donde nosotros conocemos, nadie ha señalado nunca un cuadro impresionista 
concreto en el que unos colores concretos, aplicados de una forma concreta, den lugar a un tono concreto al mezclarse a una distancia concreta en la retina del espectador. Por el contrario, el empeño por vincular a los impresionistas con la mezcla óptica está sembrado de generalizaciones y vaguedades, y está lastrado por el desliz fundamental de confundir dos fenómenos incompatibles: fusión óptica y vibración por contraste. Por poner un caso reciente, la historiadora A. M. Preckler sintetiza en palabras precisas el error instalado en el fondo de las opiniones de otros muchos colegas:

El grupo de pintores impresionistas llegó a establecer métodos completamente nuevos y revolucionarios en sus lienzos. Uno de ellos fue la "división del tono", en el cual los colores no se mezclan en la paleta al modo tradicional, sino que se aplican separados mediante cortas y ágiles pinceladas, directamente en el lienzo. Será luego, en la retina del ojo humano, donde se efectúe la "mezcla óptica", es decir, que el ojo captará, ya unidas, las numerosas y pequeñas pinceladas separadas en la tela. (Preckler, 2003, p. 321) ${ }^{1}$

Descarguemos por el momento a los pintores de cualquier intervención directa en la fabricación de esta leyenda, disculpa que en modo alguno podemos concederles respecto a otros mitos impresionistas igualmente universales. ¿A qué o a quiénes cabe entonces señalar a la hora de repartir responsabilidades? No al cálculo interesado, ni a la buena o mala fe, sino más bien a la simplificación, a esa crítica y a esa historiografía artísticas empeñadas en descubrir conexiones causales donde sólo hay accidente y, sobre todo, a una dosis no pequeña de confusión con los presupuestos estéticos y plásticos de uno de los movimientos que asumió el reto de llevar a sus últimas consecuencias el legado impresionista: el divisionismo. La coincidencia de fechas no puede ser más significativa: sólo cuando los cuadros divisionistas se dejaron ver en las exposiciones y el concepto de mezcla óptica fue moneda de cambio corriente entre pintores y críticos, sólo entonces comenzó a descubrirse mezcla óptica en los cuadros impresionistas gracias a una proyección retrospectiva fundada en una cierta semejanza formal. Nada parecido a la mezcla óptica aparece en los textos críticos del impresionismo de la década de $1870 \mathrm{ni}$ de la primera mitad del decenio siguiente, nada de fusión óptica o retiniana de los colores en las crónicas de los Duranty, Duret, Chesneau, Laforgue y Zola, y si algún comentarista -como C. Ephrussi en 1880- escribe que las realizaciones impresionistas estaban concebidas para ser miradas a distancia, 
la razón aducida no era porque fuera necesario mezclar tonos en la retina, sino para integrar en un todo coherente la pincelada quebrada y discontinua del cuadro y "alcanzar una unidad luminosa cuyos diversos elementos se funden en un conjunto indisoluble" (Ephrussi, 1997, p. 143). Ni siquiera alguien tan propenso como Van Gogh a las elucubraciones en materia artística liga a los impresionistas con la mezcla óptica cuando tiene ocasión de contemplar sus cuadros en su estancia parisina entre febrero de 1886 y el mismo mes de 1888, si hemos de juzgar a partir de las cartas que escribió en ese período. Sólo en un texto de 1880 salido de la pluma de J.-K. Huysmans a propósito de la quinta Exposición de los Independientes hallamos una referencia explícita a la mezcla óptica, en relación con un artista que, aunque él nunca aceptó para sí la etiqueta de impresionista, era una de las figuras sobresalientes de la nueva escuela: Degas. "iQué nueva aplicación desde Delacroix de la mezcla óptica, es decir, del tono ausente en la paleta, y obtenido sobre el lienzo mediante el acercamiento de dos diferentes!" (Huymans, 2002, p. 69). ${ }^{2}$

El hecho decisivo de que los divisionistas se dieran a conocer en las exposiciones independientes compartiendo paredes con los impresionistas sensu stricto contribuyó a enredar opiniones, teorías y técnicas, valorando unas obras bajo el prisma de lo que se observaba en otras con las que mantenían analogías formales en ciertos aspectos muy evidentes. La octava y última exposición impresionista (1886), bautizada "de pintura" sin más adjetivaciones, reunió a un variopinto grupo de artistas entre los que se contaban Degas, Cassatt, Guillaumin, Morisot, Gauguin y Seurat; éste último presentaba Una tarde de domingo en la Grande-Jatte (AIC). También Signac exponía varias obras, así como Pissarro, recién convertido al credo del punteado divisionista. Las tensiones habidas durante la organización de la muestra, nacidas muchas de ellas de la oposición de Degas a aceptar la presencia de Seurat y Signac, se tradujeron en la instalación de los lienzos divisionistas en una sala aparte, y parece indudable que esta presencia segregada influyó en que fueran consideradas como ejemplares de una tendencia diferenciada. La crítica que redactó P. Adam para La Revue Contemporaine llevaba por título la fórmula genérica de Pintores impresionistas y en ella podía leerse lo siguiente:

El colorido de los impresionistas más avanzados se vuelve completamente científico. Desdeñando el cocinado de los colores, la maña de las mezclas y degradados, obtienen la tinta mediante una simple yuxtaposición de tonos que, vista a cierta distancia, compone el 
valor buscado, su resultante. (Adam, 1997, p. 214)

Adam se refiere con la etiqueta de "impresionistas más avanzados" a los divisionistas, englobados, por comodidad y a falta de otra mejor, bajo una denominación ya consagrada. Como exponente de los "impresionistas menos avanzados" figuraba Guillaumin, de quien Adam escribe que "conserva aún cierto cariño a las mezclas en la paleta" (Adam, 1997, p. 214-215). Cierto cariño: se diría que, a juicio del crítico, Guillaumin -converso sólo a medias- ha comenzado ya a dividir, a explorar el terreno la recomposición retiniana, pero todavía permanece ligado parcialmente al "viejo" procedimiento de la mezcla física de los colores. No hay que asombrarse de ello: seguramente cualquiera de los veintiún cuadros suyos presentes en la exposición se hubiera prestado al establecimiento de semejanzas con los de Seurat o Signac, habida cuenta de que la factura de Guillaumin se caracterizó siempre por unas atrevidas y algo estridentes aplicaciones de colores brillantes en toques separados, que puso en práctica con una precocidad verdaderamente sorprendente. Parece, por tanto, que Adam hace pasar los lienzos impresionistas por el tamiz divisionista forzando no poco las costuras, como si observara los primeros con los anteojos que se colocó para valorar los segundos. Ésta fue una veleidad en la que nunca incurrió F. Fénéon. Soporte teórico del divisionismo y, por ello, el crítico mejor posicionado para destacar los aspectos originales de sus realizaciones, Fénéon prestó su magisterio y toda su capacidad didáctica a subrayar las diferencias entre impresionistas y divisionistas a la hora de enfrentarse a la planificación y ejecución de la obra. En un texto de 1887 resume el "espíritu de impresionismo" en cuatro líneas esenciales: proscripción de los temas históricos, alegóricos y literarios, ejecución del natural y frente al motivo, interés por el sentido emocional de los colores y, como característica más esencial, “el esfuerzo por acercarse a las brillantes luminosidades naturales" (Fénéon, 1997, p. 236). Ni una palabra de mezcla óptica, ni como medio ni como fin. En su análisis comparativo, el divisionismo ahonda en estas directrices pero lleva más lejos que sus antecesores el afán de asegurar la máxima intensidad cromática de la obra, meta que Seurat persiguió con la creación de un método que contaba con el respaldo de la ciencia del color:

La innovación de Seurat tiene por base la división científica del tono. Esto es: en lugar de mezclar sobre la paleta las pastas cuya resultante, extendida sobre la tela, proporcionará más o menos el color del objeto que hay que figurar, el pintor pondrá sobre la tela pinceladas separadas 
correspondientes unas al color local de ese objeto, otras a la cualidad de la luz que cae, otras a los reflejos proyectados por los cuerpos vecinos, otras aún a los complementarios de los colores ambientes (...). Los colores se componen sobre la retina: tenemos, pues, una mezcla óptica. (Fénéon, 1997, p. 237) ${ }^{3}$

El crítico T. Duret (que en fecha tan temprana como 1878 había publicado la primera historia del movimiento impresionista) aún reunió fuerzas en 1904 para intentar desmontar el mito, con poco éxito a tenor de lo que llegaría hasta nuestros días:

Un procedimiento nuevo aparecía, en 1886, en la última exposición colectiva de los impresionistas. Consistía en no mezclar los colores sobre la paleta para colocarlos en la tela unos junto a otros, en estado puro, en puntos o pequeñas manchas (...). Parecidas investigaciones habían sido desconocidas para los primeros impresionistas. (Duret, 1904, p. 402)

Algunos años más tarde, el poeta y crítico de arte G. Apollinaire (2001, p. 50) no creyó estéril remachar que "el primero en exponer un cuadro dividido fue Seurat, en 1886". Igual de clara estuvo la cuestión para el célebre marchante A. Vollard (1868-1939), como queda claro en un pasaje de la deliciosa autobiografía que vio la luz en 1937:

Otros pintores jóvenes, soñando con una técnica en cierto modo científica, se esforzaban por adaptar a la pintura los recientes descubrimientos de Chevreul en sus investigaciones sobre la luz (...). Para estos pintores, la mezcla de los colores la realizaba el ojo, y por eso deben ponerse tonos puros sobre el lienzo. Es el neoimpresionismo. (Vollard, 1983, p. 206)

Pero tal vez nadie mejor que los miembros de la flamante escuela para marcar distancias entre los procedimientos impresionista y divisionista, nadie más interesado que ellos para dejar claro el espacio que les separaba de la forma de hacer de los impresionistas "puros": su conciencia de grupo y su deseo de proyección en el mundillo artístico como corriente diferenciada pasaba precisamente por ello. Pissarro, que realizó un viaje de ida y vuelta entre el impresionismo y el divisionismo en menos de tres años y con idéntico 
fervor en ambas direcciones, es seguramente el más indicado para subrayar una diferencia que a ningún pintor mínimamente atento podía pasársele por alto. Cuando en 1886, poco antes de la octava exposición, explicaba por carta al marchante Durand-Ruel que el método neo-impresionista consistía en "sustituir [por] la mezcla óptica la mezcla de los pigmentos (...) porque la mezcla óptica suscita luminosidades mucho más intensas que la mezcla de los pigmentos" (Pissarro, 1978, p. 71-72), ¿qué estaba proclamando indirectamente sino que los impresionistas practicaban la segunda y no la primera? Más aún: una carta escrita a su hijo Lucien en enero del año siguiente contiene una severa crítica a varias obras de Monet por su tonalidad apagada, y las contrapone a un lienzo propio en el que "se ve realmente la ventaja de las coloraciones sin mezcla" (Pissarro, 1978, p. 101). Así pues, y a despecho de lo que postularan muchos críticos coetáneos y posteriores, si hemos de dar crédito al impresionista que más se preocupó por dotar al movimiento de un sólido soporte teórico, parece que Monet sí que mezclaba en la paleta... al menos hasta 1887.

Pero ¿qué son las palabras de un pintor o de un ramillete aislado de críticos frente a la aquilatada experiencia de tantos compañeros de profesión para penetrar en el alma de los artistas, en el laberinto de sus intenciones y en los secretos mejor guardados de sus cuadros? En el capítulo que dedicó a Pissarro en Les hommes d'aujourd'hui (1890), G. Lecomte explora la decisiva influencia que el paisajismo inglés tuvo sobre la génesis del impresionismo. A la vuelta a Francia en 1871 tras su exilio británico motivado por la guerra franco-prusiana, Monet y Pissarro habrían traído consigo la ley de los complementarios y la división del tono, aprendidos en la obra de Turner. En un abrir y cerrar de ojos, ellos y sus colegas, habiendo preparado ya el camino para dar el salto definitivo gracias a sus propias experimentaciones,

reconocieron la superioridad de la mezcla de los colores en la retina sobre la mezcla, necesariamente más oscura, que se opera en la paleta. La reconstitución óptica de los colores complementarios divididos en la tela les proporcionaba, en fin, esas rubias claridades tan pacientemente anheladas. (cit. Roque, 2009, p. 296) ${ }^{4}$

Pissarro apostaba por mezclar en la retina en la década de 1870 porque el crítico lo dijo; ¿qué importa que el propio pintor sostuviera lo contrario? 


\section{La Fragua del Mito}

Sólo unos pocos años después de la exposición en que fue presentada al público Una tarde de domingo en la Grande-Jatte y en pleno auge del divisionismo como rama puntera de la vanguardia pictórica, el mito de la mezcla óptica impresionista había arraigado ya con notable vigor. Georges Jeanniot visitó a Monet en Giverny en 1888 y parece que no vio al maestro mezclar en la paleta ni una sola vez: "[Monet] pinta a plena pasta, sin mezcla, con cuatro o cinco colores sencillos; yuxtapone o superpone tonos crudos" (cit. Wildenstein, 1986, p. 61). El confusionismo entre los métodos de trabajo impresionista y postimpresionista adquiere carta de naturaleza en el artículo Balance del impresionismo redactado por el crítico Robert de la Sizeranne para la Revue des Deux Mondes con motivo de la Exposición Universal de París de 1900:

De entrada, [los impresionistas] proscribieron de su paleta los colores neutros (...) como los marrones, no quedándose sino con colores vivos: amarillos, naranjas, bermellones, lacas, rojos, violetas, azules, verdes intensos como el veronés y el esmeralda. Reducidos a estos colores luminosos que se aproximan a los del espectro solar, se prohibieron aminorar el brillo por las mezclas en la paleta. En su última evolución, quisieron evitar no solamente la mezcla sobre la paleta y en el pincel, sino incluso, hasta cierto punto, la mezcla sobre la tela, componiendo los tonos, hasta donde les fuera posible, por pequeños fragmentos puros, unos al lado de otros. (Sizeranne, 1900, p. 642)

Naturalmente, la que el autor denomina "última evolución" del impresionismo se corresponde con el divisionismo, en el que Sizeranne detecta una aplicación científica y sistemática del procedimiento de mezcla retiniana iniciado "instintiva" o "empíricamente" por Monet y Pissarro a finales de la década de 1860, intuición que quedó confirmada gracias al estudio de los cuadros de Turner durante su exilio de 1871. Ese procedimiento especial de mezcla cromática a partir de tonos puros -mezcla que no tenía lugar en la paleta ni sobre la tela sino en la retina del espectador- no fue un método que Monet o Pissarro aplicaran de manera sistemática, sino más bien un "presentimiento de futuro o, si se quiere decirlo así, un ideal", pero lo bastante sólido como para que el divisionismo sucesor llegara a erigir sobre él toda una teoría de la ejecución pictórica centrada en la división científica del tono mediante el punteado. 
Quién sabe si porque leyera el texto de Sizeranne o cualquier otro aún más confuso en este punto, el pintor academicista español Manuel Domínguez Sánchez (1840-1906) quiso que la mezcla óptica fuese una de las "invenciones de cosecha propia en la escuela impresionista” en el discurso que leyó con motivo de su admisión en la Real Academia de Bellas Artes de San Fernando en noviembre de 1900. Habiendo recibido un premio en la Exposición Universal de París de 1878, nada tiene de raro que acudiera entonces a la capital francesa y que aprovechara para contemplar cuadros del grupo no ha mucho constituido, pero, si sucedió tal cosa, no parece que tuviera ánimo suficiente para acercar los ojos a los coloridos lienzos de los independientes, porque de lo contrario nunca habría escrito con tanta convicción que el credo impresionista estipulaba

que en lo posible no se han de mezclar tonalidades que se apagan y enfrían al mezclarlas en la paleta. Que la mezcla es mejor producirla sobre la retina del observador, aproximando entre sí los fragmentos de tonalidades puras, que pueden ejercer influencias y modificaciones unos sobre otros, reconstituyendo de esta manera la impresión visual en su integridad más completa. (Domínguez, 1900, p. 24)

La localización en el pasado de antecedentes prestigiosos que injertaran el impresionismo en la gloriosa tradición francesa se hizo también a cuenta de la mezcla óptica del color en los primeros años del siglo XX. En el capítulo de El tormento de la unidad (1901) que dedica a rastrear paralelismos entre el arte gótico francés y el impresionismo, el historiador A. Mithouard encuentra un común tratamiento de la luz y del color en los vidrieros medievales y en los pintores del aire libre, evidenciado en una paleta limitada a los tonos espectrales y, cómo no, en la fusión óptica de los colores:

Mientras que los góticos, para evitar ensuciar los tonos, modelan mediante plumeados [hachures], los impresionistas proscriben la mezcla de los tonos en la paleta. Unos y otros se contentan con un pequeño número de colores, de una gama restringida y brillante (...). De manera semejante, anticipan la reconstitución óptica y la mezcla a distancia (...). Proceden, en suma, por pequeños toques; nada de superficies monocromáticas (...). De ahí ese mosaico de rubíes, de turquesas y de esmeraldas que refulge en los rosetones de París y de Chartres. (Mithouard, 1901, p. 332-333) 
En su propio rastreo de antecedentes, el crítico C. Mauclair (1902) deja transcurrir algunos siglos y apunta a A. Watteau como el artista que "da en toda su obra un espléndido ejemplo de la descomposición razonada de los tonos" que más adelante asumirán como propio los pintores impresionistas:

El Embarque para Citera [1717, ML] es una obra maestra del alma; técnicamente, es una tela impresionista. El cielo, el follaje están tratados según el principio de la disociación y de la fragmentación de las tonalidades, recomponiéndose a alguna distancia sobre la retina del espectador, exactamente como en los cuadros de Monet. (Mauclair, 1902, p. 364)

La atribución de un propósito de mezcla óptica a casi cualquier cuadro o artista que hagan uso de una pincelada fraccionada y multicolor deviene una constante, dándose por sentado que el pintor buscaba a sabiendas lo que poco menos que en el ciento por ciento de los casos es sólo el resultado inevitable, bajo ciertas condiciones, de una forma especial de trabajar la superficie de la obra. Del mismo modo que hoy colgamos la etiqueta técnica de "impresionista" al lienzo de cualquier época que muestra una factura suelta y sumaria, existe un claro exceso en la presunción de que el pintor que coloca, unas junto a otras, pequeñas pinceladas de dos colores distintos tiene siempre por objeto la consecución de un tercer color en la retina del observador. La aplicación del color mediante toques discretos típica de muchos cuadros de A. Watteau (16841721) se presta fácilmente a equivocar la causa con el efecto, lo sucedido con lo pretendido. Haciéndose eco seguramente de la idea expuesta por Mauclair, el marchante A. Vollard preguntó a un anciano Renoir "si Watteau, en su Viaje a Citera [1717, ML], no había presentido ya la manera de Monet, con su división de tonalidades mediante capas de colores yuxtapuestos, capaces de reconstituir a la distancia, en el ojo del espectador, la coloración verdadera de las cosas pintadas”, a lo que el pintor replicó con enojo indisimulado: “¡Basta, por favor!... Recuerdo haber oído ya algo por el estilo. ¿No ha visto entonces usted nunca el Viaje a Citera? Tome usted una lupa. ¡Verá que no hay allí más que tonos mezclados!" (Vollard, 1944, p. 96-98).

Pero la superchería siguió su curso, aparentemente ciega a la evidencia ocular y sorda salvo ante las palabras de quienes la sostenían. El historiador H. Marcel mezcla en un cóctel pictórico colores brillantes y recomposición retiniana, pincelada suelta y color dividido, luz y pigmento, impresionismo y 
divisionismo, y acepta la impostura de la mezcla óptica impresionista con una naturalidad que asombra por lo que tiene de automática e irracional. Quizá por primera vez se enuncia la estrafalaria idea de que los verdes de los cuadros impresionistas no son tales, sino simplemente pinceladas de pintura amarilla colocadas junto a pinceladas de pintura azul y vistas todas ellas desde tres pasos más atrás:

Los impresionistas se percataron de que los colores mezclados perdían gran parte de la consistencia y del brillo de sus elementos constituyentes. Intentaron, pues, proceder por yuxtaposición en lugar de por mezcla, [y] hacer, por ejemplo, un verde con un azul y un amarillo situados uno al lado del otro. El ojo, a la distancia oportuna, fusiona los dos tonos. (Marcel, 1905, p. 323)

No deja de sorprender que un especialista que escribe a tan corta distancia temporal de su objeto de estudio incurra en tan clamorosa equivocación, máxime cuando por entonces todavía estaban plenamente activos los artistas más destacados del movimiento (todos salvo Sisley y Pissarro, fallecidos en 1899 y 1903 respectivamente).

El arte de mirar los cuadros, obra de divulgación que A. Beaunier consagró en 1906 a fomentar la educación del gusto entre sus conciudadanos, señala a Delacroix y a Turner como los espejos en que se miraron los impresionistas para adoptar su característica pincelada en forma de coma [touches en virgule], cada una "de un color puro, de forma que la mezcla se hace en el ojo y no sobre la tela por el pincel del artista" (Beaunier, 1906, p. 221). C. Moreau-Vauthier (1913, p. 70-71) rebotará la idea con un añadido agravante, por tratarse de un pintor que redacta un manual para uso de pintores. Ese mismo año se hace eco de la superchería el filósofo P. Souriau en su Estética de la luz:

Los matices no serán obtenidos mediante la mezcla real de los pigmentos coloreados (...) sino por mezcla óptica de los tonos previamente disociados. El artista yuxtapondrá sobre su tela, mediante toques menudos, tonos tan simples y tan diferentes como sea posible. Lo ideal sería no hacer intervenir más que los puros colores espectrales, y obtener por su fusión en la distancia todas las tintas intermedias. De este modo se alcanza una frescura, una claridad de coloración incomparables. (Souriau, 1913, p. 347) 
Cerrada la segunda década del siglo, A. Letellier (1920, p. 195) resume la "doctrina impresionista" apelando a la simplificación del claroscuro, la exclusión del betún y del negro en las sombras y "pintar con los siete colores del espectro sin mezclarlos (la distancia los combina en nuestra retina)". Letellier no puede referirse a Seurat ni a los divisionistas, a quienes ni siquiera nombra puesto que su estudio se detiene antes de la irrupción de éstos en el panorama artístico francés. Y así, encadenando declaración con declaración, para cuando el novelista, poeta y dramaturgo francés A. Lamandé pronunció en Mónaco su conferencia sobre el impresionismo (3 de enero de 1925), la afirmación de que la mezcla retiniana era práctica habitual y metódica entre los impresionistas genuinos había ingresado para siempre en el pabellón de los tópicos artísticos, conformando un cliché que se repetiría sin cesar hasta nuestros días saltando de boca en boca y sobreviviendo gracias al principio de autoridad que ennoblece los dictámenes de los expertos, abona el terreno a la credulidad y sirve de antídoto al ejercicio de la crítica fundada. La originalidad de Lamandé, empapada de espíritu positivista, radica en suponer a los pintores guiados por el propósito consciente de emular la manera en que opera la propia naturaleza, que a su parecer nunca mezcla colores (¿cómo podría hacerlo?) sino que los yuxtapone en forma de partículas vibratorias. Lamandé concibe al impresionista como un experto de la sensibilidad que trabaja con la estrecha pero rutilante paleta de los colores espectrales, como un poeta de la luz que hermana la ciencia con la estética. De este modo, la mezcla óptica conecta al impresionista con la naturaleza gracias a un proceder compartido:

Éste es el dogma, el credo de los adoradores de la luz: los colores son aglomeraciones, yuxtaposiciones, superposiciones de vibraciones luminosas. Y este credo gobierna toda su técnica. Dado que en la naturaleza los colores se forman no por mezcla sino por yuxtaposición de vibraciones, los impresionistas proceden científicamente de la misma forma. Respetan la pureza del color. No extienden sobre la tela, como los antiguos maestros, colores previamente mezclados en la paleta. Se sirven únicamente de los siete colores del prisma y, siguiendo el método de Claude Monet, los yuxtaponen en pequeñas pinceladas sobre la tela. Estos toques originan un gran número de vibraciones luminosas que, agrupándose y fundiéndose, forman en la distancia, por el juego de las combinaciones ópticas, los colores sobre nuestra retina. (Lamandé, 1925, p. 13-14). 
A estas alturas, el mito ha cobrado vida propia avalado por la repetición en cadena, el prestigio de las fuentes y el aura de sacralidad de la letra impresa. Unos confundieron vibración cromática con mezcla óptica y otros toman a aquéllos como voces autorizadas a las que acuden para dar forma a su propio parecer. Así las cosas, ¿cómo podrían hacer mella en la coraza del mito los testimonios indirectos y los contados mentís expresos provenientes de críticos y ensayistas bien informados? El historiador del arte J. Carson Webster (1944) llevó a cabo un intento tan serio como infructuoso por desligar la mezcla óptica de la técnica pictórica impresionista, trabajo al que R. Arnheim (1999, p. 343) se agarró para emitir su propia impugnación en su obra clásica Arte y percepción visual. El gran historiador del arte P. Francastel tampoco desaprovechará la ocasión en su Historia de la pintura francesa (1955) para lanzar su propio dardo contra los crédulos que repiten como un eco lo que oyen decir sin más comprobación. Quien sostiene que los impresionistas no mezclan con el pincel o que sólo emplean colores "puros" o espectrales afirma el autor notoriamente malhumorado- demuestra no haber mirado nunca de cerca un cuadro de Monet, aunque pueda servir de disculpa el argumento "de que los cuadros de Monet no están hechos para ser contemplados de cerca":

Se ha hecho constar (...) que Monet abandonó el procedimiento clásico de la mezcla de colores en la paleta y yuxtapuso directamente sobre la tela colores puros -los tonos del espectro- a fin de obtener, de acuerdo con la ley de los complementarios y del contraste simultáneo de los colores (...) la tonalidad requerida (...). Los colores de Monet no tienen nada de colores puros: para convencerse, basta compararlos con los de los pintores del siglo XX que, quizá en virtud de esta leyenda, se sirven realmente de ellos. Las pinceladas de Monet tampoco se yuxtaponen unas a otras, sino que se superponen, tanto unas sobre otras como sobre el fondo inicial, el cual, pese a lo que se ha dicho, proporciona una indicación del tono local (...). Es cierto que Monet, ayudado en esto por Manet, vio en los paisajes tonalidades y coloridos que sus predecesores no vieron o no quisieron ver. Para lograrlos, se servía de los colores utilizados en su época, los mismos que emplearan Courbet o Gustave Moreau, y nunca dejó de mezclar dos o tres de ellos para obtener el tono deseado. (Francastel, 1970, p. 316-317) 
Como el pirotécnico que pierde el control de la mecha una vez encendida y nada puede hacer para impedir la explosión, el mito de la mezcla óptica impresionista suma décadas replicándose a sí mismo y ha acabado por perfilar una superchería de dimensión comparable a la maldición de Tutankamón, al cúmulo de necedades dichas y escritas alrededor de La Gioconda y a los presuntos trastornos oculares padecidos por El Greco. Tan lejos estamos de afirmar que exista unanimidad miope en su aceptación como de sugerir que la mayor parte del edificio teórico levantado sobre el impresionismo asuma como cierto el error; tan sólo nos llama la atención que en tan corto espacio de tiempo, y acerca de cuadros que se pintaron hace no más allá de algunas generaciones, haya podido organizarse un totum revolutum de tal calibre entre vibración y fusión cromáticas, y entre impresionistas y divisionistas, como para meter a ambos en el mismo saco, como si la principal diferencia entre Monet y Seurat consistiera en que el primero hacía por intuición y tanteo lo mismo que el segundo practicaba de manera metódica, científica y racional. Lo más insólito y alarmante de la mistificación no es que haya encontrado un refugio confortable en la opinión popular, sino que reputadísimos críticos, historiadores, pedagogos y aun artistas hayan cometido el desatino de ligar el impresionismo con el ejercicio ocasional o sistemático de la mezcla óptica. De la larga relación de nombres y citas que todavía podríamos traer a colación (y que omitimos para no hacer más farragoso y repetitivo este texto), mencionaremos únicamente el caso de Josef Albers (1888-1976). Artista y teórico, profesor de la Bauhaus en Weimar y más tarde en el Black Mountain College de Chicago y en la Universidad de Yale, su dilatado magisterio en materia cromática se condensa en su obra fundamental La interacción del color (1963). Que sus páginas reúnan tantos aciertos no impide que subrayemos la flagrante confusión en que incurre su autor al dar por buena la práctica impresionista de la mezcla óptica. Albers se alinea, incluso, con aquellos que jamás han visto en un lienzo impresionista un verde mezclado, sino únicamente pinceladas separadas de amarillo y azul:

De los pintores impresionistas hemos aprendido que nunca [sic] presentaban, digamos, un verde en sí. En lugar de emplear pintura verde resultante de la mezcla mecánica de amarillo y azul, aplicaban amarillo y azul en puntitos sin mezclar, de manera que sólo se mezclaran en nuestra percepción, a modo de impresión. (Albers, 1999, p. 47) 


\section{La Contribución de los Artistas}

Más arriba, y un poco apresuradamente, descargábamos a los pintores impresionistas de cualquier cuota de responsabilidad en la formación del mito de la mezcla óptica aplicado a su propio quehacer. Ahora es el momento de matizar esta categórica exculpación enfrentando un par de casos concretos que también habrán aportado su granito de arena en el fortalecimiento de la ficción. Es cierto que no conocemos ningún testimonio salido de la boca o de la pluma de un impresionista "puro" que pueda señalarlo como practicante de la recomposición retiniana de los colores, y tampoco debemos olvidar que, salvo Vollard, parece que nunca nadie tuvo la elemental iniciativa de preguntar directamente a Monet, Renoir, Sisley o Pissarro si disponían sus colores separados sobre el lienzo con el propósito de que se fusionaran en la retina del observador.

Hasta donde ha llegado nuestra exploración, podemos asegurar que Monet nunca manifestó que empleara la mezcla óptica... pero sí -al menos en una ocasión- algo que sonó bastante parecido. Nos referimos a la entrevista concedida a F. Thiébault-Sisson en los últimos meses de 1900, en la que el pintor desgranó unas pequeñas memorias que fueron publicadas como texto seguido en el diario Le Temps en su número de 26 de noviembre bajo el título de $A \tilde{n} o s$ de adversidad. Evocando sus primeros años en París y el arranque de su vocación de pintor à plein air, explica Monet: "Estaba todavía [1867] lejos de adoptar el principio de la división de los colores [division des couleurs] que alborotó a tanta gente contra mí" (Mirbeau \& Thiébault-Sisson, 2011, p. 69). "División de los colores": he aquí una expresión peligrosamente similar a esa otra de "división del tono" que desde hacía casi quince años podía leerse una y otra vez en los textos críticos del neoimpresionismo, cuyos artistas sí aspiraban programáticamente a la mezcla óptica del color. ¿Había leído Monet el texto de P. Signac De Eugène Delacroix al neoimpresionismo (1899), donde el autor emplea repetidamente esa expresión, ligándola al divisionismo pero también, parcialmente, al impresionismo? No parece aventurado afirmarlo, como tampoco que el concepto fuese familiar a alguien que, como el pintor altamente considerado que era Monet en aquella época, debemos suponer interesado por estar al día de la actualidad artística. El error nace en el momento en que se confunde la división de los colores monetiana con la mezcla óptica. Justamente eso mismo hace Sizeranne en su Balance del impresionismo, donde considera la división del color como "el hallazgo más precioso" de la escuela y lo asimila con la fusión óptica (Sizeranne, 1900, p. 
641). Quizá Monet leyó este artículo en la Revue des Deux Mondes antes de conceder la entrevista a Le Temps a finales de aquel mismo año. Sea como fuere, todo apunta a que Monet empleó una etiqueta que no era de cosecha propia pero que le surtió un buen servicio como una manera fácil de explicar el elemento distintivo de la factura impresionista, precisamente el que marcó una de las quiebras más rotundas respecto al arte academicista de su época. Lo que por desgracia no hizo Monet, como tampoco Renoir ante Vollard años más tarde, fue aprovechar la ocasión para deshacer la idea -que ya entonces empezaba a ganar peso y que cuesta creer que él no conociera- de que esa ruptura de los colores locales por las influencias lumínicas y ambientales en un apretado enjambre cromático tuviera por objeto la reconstitución óptica de las coloraciones en la distancia.

Si nos dejamos llevar por la misma precipitación que Sizeranne y asumimos que la división de los colores impresionista y la división del tono divisionista son una única y misma cosa, entonces no carece de lógica este empecinamiento por ligar a Monet, y por extensión a todos los impresionistas puros, con la mezcla óptica del color. Observando a corta distancia muchos de sus cuadros más avanzados desde el punto de vista cromático de la década de 1880 en adelante se descubren innegables similitudes entre su factura discontinua y abigarrada y el modo de hacer de los divisionistas. Puesto que sabemos que a éstos les movía la búsqueda de la mezcla óptica, nada más fácil que atribuir a Monet idéntico propósito. La convicción, asumida por cualquiera que posea ciertas nociones de pintura, de que esas mismas coloraciones fraccionadas darían lugar a un tono turbio, parduzco, si hubiesen sido mezcladas físicamente en la paleta contribuye también a hacer más verosímil la asimilación. Otro tanto puede decirse de la textura áspera y desestructurada característica de las superficies herbáceas moteadas de flores de Renoir (Mujer con sombrilla en un jardin, 1873, MTB), por no hablar de la inaudita alfombra policroma en que resuelve el terreno descubierto por la retirada del agua en Marea baja (CAI), pintado diez años más tarde.

Sin embargo, y aunque pueda estar basada en presupuestos estilísticos semejantes o parcialmente compartidos, la técnica de Monet y Renoir carece del rigor sistemático y de la calculada premeditación que guiaban a Seurat, para quien cada color establecía una relación unívoca con otro u otros en función de criterios definidos con anterioridad, como el espacio que dicho color iba a ocupar en el cuadro y sus elementos vecinos. El procedimiento monetiano no perseguía la mezcla óptica sino, por el contrario, la vibración del color por contigüidad en el seno de un hervidero de luces policromadas, 
y esto no excluía desde luego la mezcla previa en la paleta para dar lugar a cada tinta particular. Si comparamos la atomización cromática de Bordighera (1884, AIC) con la factura ancha y sintética de Mujeres en el jardín (1867, MO), años antes de que el pintor hubiese "adoptado el principio de la división de los colores", estaremos en condiciones de entender a qué se refería Monet con esa equívoca expresión. La división de los colores significaba, en definitiva, la renuncia al color uniforme y a la pincelada fundida en beneficio del toque plural y fraccionado y de la vibración por proximidad, así como la reconstrucción de la fidelidad representativa-que no del color, puesto que éste "estaba ahí" en todo momento- cuando la mirada abarcaba a cierta distancia la superficie de la obra. Ese troceamiento cromático era uno de los aspectos que sorprendían y hasta escandalizaban a esa parte de público poco dispuesta a conceder a los cuadros impresionistas esa porción de magia que consiste en ver apenas nada o reconocer prácticamente todo según la anchura del espacio que nos separa de la obra. Así, maravillado por la transformación visual que experimentan los cuadros de Monet en función de la distancia a que son contemplados (metamorfosis operada desde lo informe a lo exquisitamente ordenado, del caos aparente a la perfecta organización), R. de Gourmont (1858-1915) escribía: "El procedimiento de Monet es la división del tono. Las telas, vistas de cerca, se asemejan a un trapo con el que se hubieran limpiado los pinceles" (Gourmont, 1931, p. 225).

Más allá de esa distancia que restituye la verosimilitud representativa y asegura la vibración cromática que imita el centelleo de la luz natural sobre la piel de los objetos, los toques coloreados comienzan a fundirse y el cuadro cobra un aspecto significativamente más apagado, aunque ese efecto queda mitigado por la saturación de los colores locales (azules del agua, verdes de la hierba, cremas y rosados de los troncos y las casas) y la oposición de las grandes superficies coloreadas del cuadro. Por tanto, que el tapiz multicolor trenzado por Monet produzca a mayor distancia cierta fusión óptica es indudable e inevitable a partes iguales; lo que resulta más discutible es que Monet pintase de esa manera con el propósito consciente y asumido de que esa mezcla tuviese lugar. Es en la tentadora identificación entre división del color y mezcla óptica donde anida la fragilidad de que adolecen numerosos señalamientos de presuntos precursores o practicantes de la fusión retiniana, incluso cuando dichos señalamientos parten de ilustres nombres de la crítica y la historia del arte. Tratándose de impresionistas, allí donde se pinta con soltura y toques enérgicos, allí donde las pinceladas entrecruzan dos o más colores, sobre todo si se trata de colores sensiblemente contrastados, enseguida 
se invoca el propósito del pintor de hacer intervenir la retina del espectador para que fabrique el color que se ha dejado adrede a medio componer. Si se pinta suelto y colorido es porque se persigue indefectiblemente el beneficio, nunca puesto en duda, que la mezcla óptica procura a la brillantez cromática en relación con la mezcla física o matérica.

Frente a un Monet poco amigo de someter su trabajo al microscopio de la elucubración intelectual, en la persona de P. Signac (1863-1935) concurre la doble dimensión de pintor divisionista y de teórico del movimiento, lo que lo convierte a priori en una voz especialmente autorizada para juzgar unos hechos y unas prácticas de las que, además, era contemporáneo estricto y que hubiera podido convalidar tratando directamente con sus protagonistas. Es imposible no atribuir una parte más o menos grande de la consagración del mito de la mezcla óptica impresionista a la difusión de su opúsculo $D e$ Eugène Delacroix al neoimpresionismo, publicado primeramente como una serie de artículos en La Revue Blanche entre mayo y agosto de 1898 y un año después en forma de libro. A lo largo de sus páginas se afana Signac por establecer un hilo lógico e inevitable entre Delacroix, el impresionismo y el divisionismo, a fin de otorgar a este último un pedigrí de dimensión histórica: el de un movimiento que hereda y lleva hasta sus últimas consecuencias el impulso de liberación cromática y una forma de hacer que arrancó décadas atrás en la colosal figura del autor de Las matanzas de Quíos y tuvo en Monet, Renoir, Sisley y Pissarro sus dignos sucesores. Para situar a Delacroix en el punto de partida moderno de la mezcla retiniana, Signac acude a los textos del eminente C. Blanc (1813-82) y a un puñado de citas del pintor romántico, cuyo significado y presunto carácter programático fuerza en ocasiones a fin de que encajen en su andamiaje argumental. El volumen arranca con una tajante declaración de paternidad del principio divisionista, pero esta atribución queda matizada con el reconocimiento de la herencia recibida: "Los artistas neoimpresionistas son quienes han instaurado y (...) desarrollado la técnica llamada de la división, empleando como medio de expresión la mezcla óptica de los tonos y las tintas" (Signac, 1943, p. 7). Los otorgantes de este legado no son otros que Delacroix y los pintores impresionistas, una suerte estos últimos de "paleodivisionistas" ávidos de luz y de exaltación cromática pero dueños de una técnica apresurada e imperfecta que sólo les permite recorrer la mitad del camino. Los impresionistas limpian y simplifican la paleta aún sombría de Delacroix, la liberan de los betunes y de los pardos acomplejados y la reducen a unos pocos tonos espectrales (Signac, 1943, p. 49). Continúan mezclando en la paleta como sus predecesores, pero, incluso cuando evitan esa tentación y 
optan por explotar la fusión óptica, la acumulación desordenada y urgente de las pinceladas frescas funde físicamente los colores más dispares en el lienzo, "y esas mezclas repetidas de moléculas enemigas extienden sobre la tela un gris que no es ni óptico ni físico sino pigmentario y deslucido, lo cual atenúa considerablemente el esplendor de la pintura" (Signac, 1941, p. 51).

Frente al impresionista de proceder un poco atolondrado, el cromoluminarista "evita mancillar la pureza de sus colores y los encuentros de elementos contrarios en el soporte" (Signac, 1943, p. 59). La aplicación de los tonos mediante un ritmo lento y cuidadoso de pincelada dividida garantiza la limpieza del color tanto en la paleta como en la tela, y por ende la irradiación cromática de la obra y el esplendor de las combinaciones retinianas. En el esquema en que resume las sucesivas aportaciones de los tres grandes hitos de la pintura del siglo XIX en la conquista del colorido con mayúsculas, Signac (1943, p. 80) descubre sus cartas de par en par y hace encajar el impresionismo como un eslabón necesario entre los empeños paralelos de Delacroix y de los neoimpresionistas, metódicos y disciplinados ambos por igual: el romántico, que practica la mezcla en la paleta y la mezcla óptica con propósito científico, aunque se mantenga fondeado a menudo en la severidad cromática del clasicismo; el impresionismo, que mezcla en la paleta y ocasionalmente en la retina pero haciendo uso de una técnica puramente instintiva y en consecuencia tosca; el neoimpresionismo, por fin, síntesis superadora de los anteriores, que explota únicamente la mezcla óptica retomando el espíritu reglamentado de Delacroix que los impresionistas desoyeron para ganar, a cambio, la urgencia de la realización, urgencia que a la postre empaña sus anhelos de alcanzar la máxima luminosidad de que es posible su paleta prismática. En pocas palabras, el neoimpresionismo amasa el cientifismo de Delacroix con el colorido exaltado de los impresionistas, llevando la mezcla óptica hasta un grado de rendimiento colorista que no estuvo al alcance ni del primero (por su paleta de clave media o baja) ni de los segundos (por su ejecución apresurada e instintiva).

Curiosamente, Signac ya era para entonces plenamente consciente de que una pincelada tan atomizada como la empleada por Seurat en Las modelos (1886-88, BF) era más un inconveniente que una virtud en lo tocante a la brillantez del efecto cromático fruto de la fusión retiniana (Cachin, 2000, p. 57), pero esta certidumbre no impidió que en su oda a las excelencias de la mezcla óptica se mencione a los impresionistas como practicantes convencidos, aunque esporádicos, de la misma. Lo que para Signac era un ejercicio ocasional e imperfecto del grupo encabezado por Monet fue después 
tomado por una conducta asidua y sistemática, en buena medida como consecuencia de una generalización errónea hecha a partir de lo leído en De Eugène Delacroix al neoimpresionismo y replicado de firma en firma con el aval de la respetabilidad de los expertos. Que el concepto monetiano de la división de los colores bebiese de esa fuente o de otra secundaria es algo que sólo podemos presumir, pero homologar división del tono y mezcla óptica es ir demasiado lejos por mucho que lo uno conduzca a lo otro bajo ciertas circunstancias. En nuestros días, la historiadora ya mencionada A. M. Preckler (2003, p. 321) persiste en esta identificación extraviada. En su propósito -seguramente influido por la lectura de Signac- de hilar los procedimientos técnicos de impresionismo y divisionismo sólo encuentra una diferencia de grado en la forma que escogen uno y otro a la hora de aplicar los colores como toques separados miscibles a distancia.

Asombrosamente, la interpretación descarriada de la división de los colores parece salpicar incluso a Cézanne. Poco sabemos acerca de cuánta reelaboración y de aportación propia hay en las conversaciones que Joachim Gasquet dijo transcribir en su clásico Cézanne. Lo que vi y lo que me dijo (1921), pero uno no puede evitar un gesto de sorpresa al toparse con un pasaje en el que el pintor, rememorando la influencia que ejerció Pissarro en los inicios de su propia vocación, declara: "El impresionismo es, verdad, la mezcla óptica de los colores, ¿comprende?, la división de tonos en la tela y la reconstrucción en la retina (Gasquet, 2009, p. 187). ¿Quién habla aquí? ¿Cézanne? ¿Gasquet? ¿Cézanne pasado por el tamiz de Gasquet? ¿La leyenda por boca de Gasquet? ¿Un Cézanne que confunde lo que sabe con lo que ha leído u oído? Cualquiera de estas posibilidades se nos antoja igualmente llamativa tratándose de un artista que cargó sobre sus pinceles la tarea de trascender el impresionismo y cuya obra abonó el semillero que abrió a la pintura las puertas de la modernidad. ${ }^{5}$

Recapitulemos. Creemos haber demostrado que los impresionistas nunca hicieron un uso consciente de la mezcla óptica, así como que la falaz conexión entre ambos arranca en un momento concreto: la aparición en primera fila de la escena artística de los cuadros divisionistas en la exposición de los independientes de 1886, octava y última del grupo. Sólo a partir de ese momento crucial las opiniones críticas, alimentadas por declaraciones más o menos confusas o interesadas de algunos artistas, comienzan a atribuir a los impresionistas genuinos, incluso en una época muy temprana de su evolución, propósitos de mezcla retiniana como alternativa a la mezcla matérica en la 
paleta o sobre el lienzo, a fin de obtener, supuestamente, coloraciones más frescas y rutilantes. No es éste el momento para refutar la fábula previa, creada por C. Blanc y explotada a conciencia por Signac, de que Delacroix planteó mezclas ópticas en algunos de sus lienzos más memorables, como tampoco lo es para acotar en su justa medida la idea de que los mismos divisionistas la emplearon con profusión. Tales asuntos serán objeto de futuras exploraciones; lo que nos importaba ahora era contribuir al desmontaje de uno de los mitos más obstinados del movimiento impresionista, mito que, por añadidura, concede a la mezcla óptica unas posibilidades pictóricas fuera de toda lógica y medida, rayanas en lo sobrenatural. Cuando el satírico Bertall describió en 1876 la nieve pintada por Monet como un "tapiz de lanas blanca, azul y verde" y la orilla de un río como "tejida de lana y algodón de cinco colores" (cit. Thomson, 2001, p. 190), ningún abogado de la causa salió en defensa del artista alegando que la fusión óptica de dichas tonalidades produce "mejores coloraciones" (más verosímiles, más intensas, más puras) que si hubiese mezclado los toques previamente en la paleta y aplicado el producto resultante. Y si nadie lo hizo, ni directa ni indirectamente, fue porque Monet nunca pretendió tal cosa... siquiera porque, como Signac comenzaba a tener claro en 1897, la fusión retiniana hubiese arruinado, como la matérica en mayor medida, el efecto cromático perseguido.

Pocos casos ejemplifican mejor el aplastante peso que la opinión egregia ejerce en ocasiones sobre la razón y la evidencia que el del anatomista italiano Mondino di Luzzi (1270-1323). En el curso de sus disecciones practicadas en cadáveres de ajusticiados, Mondino sostuvo hígados en sus propias manos, los examinó cuidadosamente y describió el órgano en su obra Anatomía (1316), de enorme difusión e influencia en su época. Pero, si hemos de creer la descripción de Mondino, el hígado consta de cinco lóbulos y no de tres, como sucede en realidad. ¿Por qué? Porque Mondino sabía que el gran Galeno había dejado escrito once siglos antes que el hígado humano tiene cinco lóbulos. ¿Y de dónde obtuvo Galeno esa idea? No desde luego de abrir cadáveres humanos... sino cerdos, cuyo hígado posee en efecto cinco lóbulos (Glasscheib, 1964, p. 268). La reacción de muchos expertos ante los cuadros impresionistas (de esos expertos que dicen ver verdes sin verde, o azules que chispean por contener, indiferenciables por la distancia, motas anaranjadas, o marrones hechos de puntos multicolores) se asemeja a la reacción de Mondino cuando observó el hígado recién extraído del abdomen de un desdichado: entre creer lo que veía y creer a Galeno, optó por lo segundo. ¿O no será, tal 
vez, que sus ojos vieron realmente en el hígado del hombre lo que sabían que tenían que ver, lo que esperaban encontrar? O puede que Mondino descubriera con estupor algo distinto y, tras vacilar un instante, sacudiera la cabeza en un gesto de claudicación y se preguntara a sí mismo: “¿Quién soy yo para contradecir a Galeno?".

\section{Notas}

${ }^{1}$ La autora sostiene a continuación que los impresionistas, en aplicación de los descubrimientos de Chevreul, empleaban únicamente los seis colores primarios y secundarios, pero es ambigua al indicar si obtenían esos secundarios por mezcla óptica de los primarios aplicados separadamente o si, simplemente, los adquirían ya compuestos en tubo.

${ }^{2}$ Huelga decir que la técnica de Degas tampoco pretende la mezcla óptica, sino justamente lo contrario.

${ }^{3}$ No descarguemos sin embargo a Fénéon de su propia cosecha de inexactitudes en éste y otros textos, fundamentalmente su asimilación entre síntesis óptica y síntesis aditiva y su creencia de que el efecto de vibración cromática es compatible con la mezcla óptica cuando son factores que se excluyen mutuamente.

${ }^{4}$ Lecomte incurre en el mismo error que su colega Fénéon. Mezcla óptica y contraste de tonos se oponen por definición: la fusión óptica anula el contraste, y si se percibe contraste es que no se verifica fusión óptica.

${ }^{5}$ R. Shiff ha analizado con gran hondura la técnica pictórica de Cézanne y de los impresionistas oponiéndola a la factura académica de su tiempo y no dice una sola palabra sobre el uso de la mezcla óptica ni en uno ni en otros (Shiff, 2002, p. 143-171, 255-274 y 301-334).

\section{References}

Adam, P. (1997). Pintores impresionistas. En G. Solana, El impresionismo: la visión original. Antología de la crítica de arte (1867-1895) (págs. 213-217). Madrid: Siruela.

Albers, J. (1999). La interacción del color. Madrid: Alianza.

Apollinaire, G. (2001). Los pintores cubistas. Madrid: Machado Libros.

Arnheim, R. (1999). Arte y percepción visual. Madrid: Alianza.

Beaunier, A. (1906). L'art de regarder les tableaux. París: Émile Lévy

[Accesible en: http://gallica.bnf.fr/ark:/12148/bpt6k5599764t.

$\mathrm{r}=$ beaunier.langES].

Cachin, F. (2000). Signac. Catalogue raisonné de l'oeuvre peint. París: 
324 Diego Gómez - Mito mezcla óptica impresionista

Gallimard.

Carson Webster, J. (1944). The technique of impressionism: a reappraisal.

College Art Journal 1(3-22). Recuperado de http://www.jstor.org/discov er $/ 10.2307 / 773614$ ?uid=3737952\&uid $=2129 \& u i d=2 \& u i d=70 \& u i d=4 \&$ s $\mathrm{id}=21102517273677$

Domínguez, M. (1900). Discursos leídos ante la Real Academia de Bellas Artes de San Fernando en la recepción pública del Excmo. Sr. D.

Manuel Domínguez el día 4 de noviembre de 1900. Madrid: Est. Tip. de la viuda é hijos de Tello.

Duret, T. (1904). Pissarro. Gazette des Beaux-Arts (mayo de 1904), 395-405

[Accesible en: http://gallica.bnf.fr/ark:/12148/bpt6k203163q].

Ephrussi, C. (1997). Exposición de los artistas independientes. En G. Solana, El impresionismo: la visión original. Antología de la crítica de arte (1867-1895) (págs. 143-148). Madrid: Siruela.

Fénéon, F. (1997). El impresionismo. En G. Solana, El impresionismo: la

visión original. Antología de la crítica de arte (1867-1895) (págs. 235240). Madrid: Siruela.

Francastel, P. (1970). Historia de la pintura francesa. Madrid: Alianza. Gasquet, J. (2009). Cézanne. Lo que vi y lo que me dijo. Madrid: Gadir. Glasscheib, H. S. (1964). El laberinto de la medicina. Errores y triunfos de la terapéutica. Barcelona: Destino.

Gourmont, R. d. (1931). Promenades philosophiques. París: Mercure de France [Accesible en: http://gallica.bnf.fr/ark:/12148/bpt6k23495q.

$\mathrm{r}=$ gourmont + promenades.langES].

Huymans, J.-K. (2002). El arte moderno/Algunos. Madrid: Tecnos/Alianza. Lamandé, A. (1925). L'impressionnisme dans l'art et la littérature.

Principauté de Monaco: Societé de Conferences.

[Accesible en: http://gallica.bnf.fr/ark:/12148/bpt6k719364.

$\mathrm{r}=$ lamand $\% \mathrm{C} 3 \% \mathrm{~A} 9+$ impressionnisme.langES].

Letellier, A. (1920). Des classiques aux impressionnistes. París: Éditions Ernest Leroux.

Marcel, H. (1905). La peinture française au XIXee siècle. París: A. Picard \& Kann.

Mauclair, C. (1902). Les précurseurs de l'impressionnisme. La Nouvelle Revue (julio-agosto de 1902), 359-371

[Accesible en: http://gallica.bnf.fr/ark:/12148/bpt6k36044n.image. langES.r=mauclair\%20nouvelle\%20revue \%20precurseurs].

Mirbeau, O., \& Thiébault-Sisson, F. (2011). Claude Monet y Giverny, 
seguido de Claude Monet, discípulo de nadie y de Años de adversidad, entrevista de F. Thiébault-Sisson a Claude Monet. Palma de Mallorca: José J. de Oñaleta.

Mithouard, A. (1901). Le tourment de l'unité. París: Societé du Mercure de France [Accesible en: http://gallica.bnf.fr/ark:/12148/bpt6k5659784q. $\mathrm{r}=$ mithouard+tourment.langES].

Moreau-Vauthier, C. (1913). La peinture. Les divers procédés. Les maladies des couleurs. Les faux tableaux. París: Hachette.

Pissarro, C. (1978). Cartas a Lucien. Barcelona: Muchnik Editores.

Preckler, A. M. (2003). Historia del arte universal de los siglos XIX y XX (tomo I). Madrid: Editorial Complutense.

Roque, G. (2009). Art et science de la couleur. Chevreul et les peintres, de Delacroix à l'abstraction. París: Gallimard.

Shiff, R. (2002). Cézanne y el fin del impresionismo. Madrid: Machado Libros.

Signac, P. (1943). De Eugenio Delacroix al neoimpresionismo. Buenos Aires: Poseidón.

Sizeranne, R. d. (1900). L'art à l'exposition de 1900 (II). Le bilan de l'impressionnisme. Revue des Deux Mondes (junio de 1900), 628-651

[Accesible en: http://gallica.bnf.fr/ark:/12148/bpt6k871895.r=sizeranne + bilan + revue + deux + mondes.langES].

Souriau, P. (1913). L'Esthétique de la lumière. París: Hachette.

Thomson, B. (2001). El impresionismo. Orígenes, práctica y acogida. Barcelona: Destino.

Vollard, A. (1944). La vida y la obra de Pierre-Auguste Renoir. Buenos Aires: Poseidón.

Vollard, A. (1983). Memorias de un vendedor de cuadros. Barcelona:

Destino.

Wildenstein, D. (1986). Giverny o la conquista de la absoluto. En VVAA, Claude Monet (catálogo de la exposición celebrada en el Museo Español de Arte Contemporáneo, 29 de abril a 30 de junio de 1986 (págs. 53-81). Madrid: Ministerio de Cultura-Fundación para el Apoyo de la Cultura. 
Localizaciones de cuadros: abreviaturas

AIC Art Institute of Chicago (Chicago, EEUU)

BF Barnes Foundation (Philadelphia, EEUU)

CAI Clark Art Institute (Massachusetts, EEUU)

MO Museo de Orsay (París, Francia)

MTB Museo Thyssen-Bornemisza (Madrid, España)

Diego Gómez Sánchez: Doctor en Bellas Artes. Profesor del Departamento de Arte de la Facultad de Bellas Artes de Cuenca (Universidad de Castilla-La Mancha).

Contact Address: C/ Santa Teresa Jornet, s/n. 16071 Cuenca. (España).

E-mail address: Diego.GSanchez@uclm.es 